9-1-1994

\title{
Fathers' Trait Verbal Aggressiveness and Argumentativeness as Predictors of Adult Sons' Perceptions of Fathers' Sarcasm, Criticism, and Verbal Aggressiveness
}

\author{
Michael J. Beatty \\ James R. Zelley \\ Jean A. Dobos \\ Jill E. Rudd \\ Cleveland State University, J.RUDD@csuohio.edu
}

Follow this and additional works at: https://engagedscholarship.csuohio.edu/clcom_facpub

Part of the Interpersonal and Small Group Communication Commons

How does access to this work benefit you? Let us know!

\section{Publisher's Statement}

This is an Accepted Manuscript of an article published by Taylor \& Francis in Communication Quarterly on 01/09/1994, available online: http://www.tandfonline.com/[10.1080/ 01463379409369946.

\section{Recommended Citation}

Beatty, Michael J.; Zelley, James R.; Dobos, Jean A.; and Rudd, Jill E., "Fathers' Trait Verbal Aggressiveness and Argumentativeness as Predictors of Adult Sons' Perceptions of Fathers' Sarcasm, Criticism, and Verbal Aggressiveness" (1994). Communication Faculty Publications. 63.

https://engagedscholarship.csuohio.edu/clcom_facpub/63

This Article is brought to you for free and open access by the School of Communication at EngagedScholarship@CSU. It has been accepted for inclusion in Communication Faculty Publications by an authorized administrator of EngagedScholarship@CSU. For more information, please contact library.es@csuohio.edu. 


\title{
Fathers' Trait Verbal Aggressiveness and Argumentativeness as Predictors of Adult Sons' Perceptions of Fathers' Sarcasm, Criticism, and Verbal Aggressiveness
}

\author{
Michael J. Beatty, James R. Zelley, Jean A. Dobos, \\ and Jill E. Rudd
}

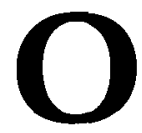

ver the past few years, the relationship between men and their fathers has gained popularity as a subject of public discussion. Since the publication of Robert Bly's 1990 bestseller, Iron John, numerous writers have expounded on the theme (e.g., Farmer, 1992; Lee, 1987, 1991; Osherson, 1992; Pittman, 1993; Vogt \& Sirridge, 1991). Programs such as "A Gathering of Men" and "Save the Males," in which the social consequences of father-son relationships are explored, have been aired by PBS. Indeed, the premise that tension between men and their fathers is commonplace underlies motion pictures such as "Dad," "Nothing in Common," and "Memories of Me." 
Recently, Beatty and Dobos (1992a, 1992b, 1993a, 1993b, 1993c) have begun to investigate dimensions of the interpersonal relationships between men and their fathers. Within this line of research, a stream of studies shows that men's reports of sarcasm and criticism received from fathers, especially during disagreements, correlate negatively and significantly with men's perceptions of the quality of that relationship (Beatty \& Dobos, 1992b, 1993b). For example, perceived sarcasm and criticism from father correlate negatively and significantly with adult sons' reports of satisfaction with their relationships with their fathers (Beatty \& Dobos, 1992b). Furthermore, other studies indicate that sarcasm and criticism from father negatively influence men's relational partners' perceptions of men's listening behavior (Beatty \& Dobos, 1993b) and increase partners' reluctance to interact with those men (Beatty \& Dobos, 1993c).

Although reports of sarcasm and criticism have been linked to important communication variables, the source of those perceptions is yet undocumented. In the present study, we examined the degree of correspondence between men's perceptions of interactions with fathers and their fathers' reports. Specifically, men's perceptions of fathers' verbal aggressiveness in general and sarcasm and criticism in particular were correlated with their fathers' self-reported argumentativeness (Infante \& Rancer, 1982) and verbal aggressiveness (Infante \& Wigley, 1986).

\section{Conceptual Framework}

In 1987, Infante conceptualized aggressive communication along a constructivedestructive continuum. The destructive pole of the continuum is represented by verbal aggressiveness, a subset of hostility. Argumentativeness, a subset of assertiveness, was viewed as a constructive form of aggressive communication. In the present study, we argue that adult sons' reports of sarcasm and criticism from fathers, which according to the extant father-son research are destructive forces in men's social relationships, are not independent of fathers' predispositions to employ destructive forms of communication. Rather, we propose that men's perceptions of fathers' sarcasm and criticism are interpersonal consequences of fathers' verbal aggressiveness.

\section{Fathers' Verbal Aggressiveness}

Infante's (1987) essay on verbal aggressiveness provides a useful framework for studying the nature and substance of men's reports of father messages. The rationale for expecting an association between men's reports and fathers' verbal aggressiveness is four-fold. First, men's reports of fathers' sarcasm and criticism can be viewed as perceptions of fathers' verbal aggressiveness. According to Infante and Wigley (1986), verbal aggressiveness represents a tendency to attack the self-concepts of individuals instead of or in addition to their positions on communication topics. In their initial study, Beatty and Dobos (1992b) derived the items that were ultimately used to measure father sarcasm and criticism from men's essays about their fathers. Adjectives and descriptive phrases were cast into bipolar adjective scales and factor analyzed, producing the two measures. Important to the present study, the negative poles of some items (e.g., insulting, judgmental) were suggestive of personal attack whereas some positive poles (e.g., praising, approving) were indicative of attempts to bolster self-esteem. Thus, the content of the sarcasm and criticism scales appears to implicate verbal aggressiveness.

Second, men's reports of fathers' sarcasm and criticism correlate with indices of relational quality in a manner consistent with Infante's conceptualization. Infante (1987) points out that while verbal aggressiveness sometimes produces constructive consequences, 
its effects are "almost always destructive" (p. 165) in interpersonal relationships. Furthermore, productive forms of communication facilitate relational satisfaction whereas destructive forms produce dissatisfaction. In general, therefore, we would expect a negative association between perceived verbal aggressiveness and relationship satisfaction. Consistent with this expectation, Beatty and Dobos (1992b) found that men's reports of sarcasm and criticism correlate moderately and significantly with men's satisfaction in father-son contexts (Beatty \& Dobos, 1992b). In subsequent research Beatty and Dobos (1993b) reported moderate and negative correlations between men's reports of confirmation from father, another measure of relationship quality, and sarcasm and criticism from father.

Third, Infante (1987, pp. 161-162) proposes and presents evidence for a personalitybased conceptualization of verbal aggressiveness. Under this view, verbal aggressiveness represents a stable tendency or predisposition to employ aggressive tactics. Although situational influences contribute to any single aggressive act, the personality-based orientation toward the construct suggests that verbally aggressive individuals are expected to employ destructive forms of communication more often than do their more constructive counterparts. Importantly, in published studies (Beatty \& Dobos, 1992b, 1993b), men were asked to report fathers' typical style of interacting with them. Although some fathers might respond to their adult sons in a manner different from the ways they interact with others, the personality-based nature of verbal aggressiveness suggests that, in general, fathers' level of verbal aggressiveness should be fairly stable across contexts, including father-son dyads.

Finally, hints about men's perceptions of fathers' verbal aggressiveness abound in the contemporary men's literature (Bly, 1990; Farmer, 1992; Lee, 1987, 1992; Osherson, 1986, 1992; Pittman, 1993; Vogt \& Sirridge, 1991). Reflecting on his experiences during men's gatherings, Bly (1990, p. 116) writes of the sarcasm, ridicule and rejection that many men expect from their fathers. Similarly, Lee (1987) recalls that "I was never able to tell my father how I felt. I was scared of ridicule and rejection" (p. 24). According to Lee (1987), this apprehension was based on experience in the form of "too many encounters with an angry father" (p. 22). Psychotherapist Samuel Osherson (1986) quotes one of his clients: "Whenever I discipline my son, I find myself yelling at him . . . in the same voice I remember my father using" (p. 192). These and numerous other personal accounts contained in the men's literature point toward potentially destructive elements of fathers' messages. Clearly, ridicule, rejection and sarcasm constitute interpersonally debilitating personal attacks rather than attacks on positions. For example, ridicule in particular is indicative of verbally aggressive communicators (Infante, Riddle, Horvath, \& Tumlin, 1992). If accurate, the observations in the men's literature are suggestive of fathers' verbal aggressiveness.

\section{Fathers' Argumentativeness}

In contrast to verbal aggressiveness, argumentativeness refers to the predisposition to defend positions on controversial issues while attempting to refute others' positions (Infante \& Rancer, 1982). As mentioned, argumentativeness is generally constructive in interpersonal relationships. However, it was included in the present study as a control variable. While we contend that adult sons' perceptions of sarcasm and criticism are reasonably accurate interpretations of fathers' verbally aggressive communication, it is necessary to ensure that these perceptions are not misinterpretations of argumentative messages. Although not expected, it is possible that fathers' argumentative responses, while intended to be constructive, contribute to men's perceptions of overall fathers' verbal aggressiveness.

Previously cited published studies indicate that men's evaluations of relationship quality regarding their fathers appears to be heavily influenced by the amount of perceived criticism received from their fathers. Supportive reactions from fathers, on the other hand, tend to 
increase men's satisfaction and sense of confirmation. Similarly, the bulk of writing about men and their fathers, which is based on observations of men's groups, underscores their desire for support, respect, and confirmation from fathers (Bly, 1990; Farmer, 1992; Lee, 1987, 1991; Osherson, 1992; Pittman, 1993; Vogt \& Sirridge, 1991). Inherent in even constructive arguments, however, are elements of evaluation. Arguments, reasoning and evidence are weighed, challenged, and frequently rejected. Indeed, some published research (Rancer, Baukus, \& Infante, 1985; Rancer, Kosberg, \& Baukus, 1992) has shown that it is often difficult for people to distinguish between attacks on positions and personal attacks. Thus, it is possible that men construe fathers' argumentativeness as aggression, especially if they perceive a critical subtext to fathers' arguments.

In addition, the behaviors of highly argumentative communicators might be perceived as aggressive. One study (Infante, 1981) found that observers perceive such persons as set in their positions, willing to attack and defend positions and expert in the topic of discussion. In contrast, low argumentative individuals "may be more inclined to accept another person's view in order to keep an argument from developing (Infante, 1981, p. 271). If men do in fact desire support and acceptance from their fathers, relatively nonargumentative fathers would be preferable to argumentative ones. Argumentative fathers' responses to son's plans and ideas might be regarded as criticism, especially if such fathers address their sons' positions on topics without maintaining sons' self-concepts. Infante (1987) reminds us that arguing competently in interpersonal contexts requires the ability "to manage interpersonal relations during the argument" (p. 176). Including argumentativeness in the present study permitted us to control for its effects when examining the relationship between men's perceptions of their fathers' verbal aggressiveness.

\section{Men's Perceptions of Fathers' Messages}

In addition to perceived sarcasm and criticism from father, men's global assessments of fathers' verbal aggressiveness were included as predictors of fathers' self-reported aggressiveness. Although conceptually and probably empirically related to sarcasm and criticism, perception of general verbal aggressiveness can be viewed as a broader construct. It is possible that fathers' verbal aggression encompasses more than sarcasm or criticism. Thus, including a global measure of perceived verbal aggressiveness affords a test of the general accuracy of men's perceptions about their fathers beyond that provided by the relatively specific sarcasm and criticism measures.

\section{Hypothesis}

Although the preceding discussion links fathers' tendencies toward argumentativeness and aggressiveness with adult sons' perceptions of their fathers, the degree of correspondence between fathers' and sons' reports remains an empirical question. If men's reports of their fathers' verbal tendencies are accurate, the following hypothesis should be confirmed:

$\mathrm{H} 1$ : Controlling for fathers' argumentativeness, fathers' verbal aggression will account for a significant portion of variance in men's reports of fathers' sarcasm, criticism, and general verbal aggressiveness.

Clearly, the observation of substantial correspondence regarding the hypothesis would provide strong validity evidence for men's reports of their fathers' communication. On the other hand, a low level of correspondence would greatly complicate interpretations of extant adult son-father research. The value of men's perceptions of their father in explaining aspects of their social behavior and internal states has already been documented. However, 
low correspondence between son's perceptions and fathers' reports of verbal aggressiveness would be inconsistent with the current assumption that men's perceptions are basically accurate reports of their fathers' verbal aggressiveness.

\section{Method}

\section{Procedure}

Seventy-four pairs of men $(M$ age $=29.35)$ and their fathers $(M$ age $=57.36)$, drawn from business as well as from a college population, agreed to participate in the present study. The fathers were told that they were participating in a survey of attitudes about communication. A packet containing measures of argumentativeness, verbal aggressiveness, and demographic questions was administered to the fathers. Their adult sons, on the other hand, were told that they were participating in a study of father-son relationships. They responded to questionnaires that included measures of their fathers' sarcasm, criticism, and verbal aggressiveness.

Those participating in the present study had agreed to (1) distribute the appropriate questionnaires to either their fathers or adult sons, (2) complete the remaining questionnaire, (3) refrain from discussing responses until completion and (4) return both packets in sealed envelopes.

\section{Predictor Variables}

Infante and Wigley's (1976) twenty-item measure of verbal aggressiveness was used to measure fathers' perceived level of verbal aggressiveness. Although shorter versions have been employed (Infante, Chandler, \& Rudd, 1989; Sabourin, Infante, \& Rudd, 1993), we administered the longer version because it provides a more comprehensive measure of the construct. Given that our purpose was to assess the accuracy of sons' reports, the broader assessment of the construct seemed sensible. In previous research the measure has demonstrated considerable reliability and validity. The alpha reliability coefficient was .83 in the present study.

Infante and Rancer's (1982) twenty-item measure of argumentativeness was employed as the index of fathers' argumentativeness. Similar to the verbal aggressiveness measure, the longer version of argumentativeness provided a more comprehensive assessment of argumentativeness. As a control variable, the longer version provides a more rigorous test of the hypothesis. In the present study, the alpha reliability coefficient was .89 for the measure.

\section{Dependent Variables}

The measure of fathers' sarcasm and criticism developed by Beatty and Dobos (1992b) were employed in the present study. Each measure consists of seven-point bipolar adjective scales (Sarcasm scales were: Sarcastic-Not Sarcastic, Insulting-Praising, Gentle-Harsh, HostileAmiable, and Hypocritical-Consistent. Criticism scales were: Critical-Noncritical, JudgmentalNonjudgmental, Evaluative-Nonevaluative, Disapproving-Approving). ${ }^{1}$ Participants were instructed to respond to these items in terms of "father's typical communication style when you talk to him." In the father-adult son studies previously cited, correlations between these measures and other variables have been consistent with theoretical expectations for measures of sarcasm and criticism. Alpha reliability coefficients for sarcasm and criticism were .74 and .69 , respectively.

The verbal aggressiveness measure described previously waš administered to sons with 
instructions to respond in terms of how well each item described their fathers' communication. The verbal aggressiveness scale has been used successfully as an "other report" in previous research (Infante, Chandler, \& Rudd, 1982; Sabourin, Infante, \& Rudd, 1993). In the present study, the alpha reliability for the measure was .91 .

\section{Results}

Means and standard deviations for each variable are presented in Table 1. Correlation coefficients between the predictor and dependent variables are reported in Table 2.

The effects of fathers' verbal aggressiveness on men's perceptions of their fathers' sarcasm, criticism, and general verbal aggressiveness, controlling for fathers' argumentativeness, were examined using a multivariate multiple regression model derived from a correlation matrix in which the coefficients were corrected for attenuation. An overall model consisting of fathers' argumentativeness and fathers' verbal aggressiveness as predictors explained $39.32 \%$ of the variance in the dependent variable set $(M R=.63 ; F=6.62$, $d f=6 / 140, p<.0001)$. The singular contribution of fathers' argumentativeness, which was entered first in the equation, to the dependent variable set was 12.9 percent $(R=.36$; $F=3.48 ; d f=3 / 71, p<.02$ ) whereas fathers' verbal aggression contributed $30.05 \%$ of

TABLE 1 Means and Standard Deviations for All Variables

\begin{tabular}{lcc}
\hline \multicolumn{1}{c}{ Variable } & $M$ & $S d$ \\
\hline Fathers & & \\
Verbal aggressiveness & 43.47 & 10.99 \\
Argumentativeness & 59.78 & 12.70 \\
Adult Sons & & \\
Pereceived Sarcasm & 16.75 & 5.25 \\
Perceived Verbal Aggressiveness & 50.49 & 13.72 \\
Perceived Criticism & 21.86 & 5.28 \\
\hline
\end{tabular}

the unique variance in the dependent variable set (multivariate partial $r=.56 ; F=10.19$; $d f=3 / 70, p<.0001)$.

Follow-up univariate analyses indicated that the model explained $25.2 \%$ of the variance in men's perceptions of their fathers' general verbal aggressiveness $(F=12.13 ; d f=2 / 72$, $p<.0001)$. Fathers' argumentativeness did not contribute significantly to the equation (squared partial $r=.03 ; t=0.02 ; d f=1 / 73 ;$ n.s.). However, as predicted, fathers' verbal aggressiveness accounted for a significant portion of variance in men's perceptions of fathers' general level of verbal aggressiveness (squared semipartial $r=.22 ; t=4.58$, $p<.0001$ ).

The univariate analyses for sarcasm indicated the predictors accounted for $16.32 \%$ of variance $(F=7.02, d f=2 / 72, p<.001)$. As in the analyses for general verbal aggressiveness, fathers' argumentativeness failed to explain a significant portion of variance (squared partial $r=.03 ; t=.04$, n.s.). Fathers' verbal aggressiveness, however, contributed significantly to the prediction of their adult sons' reports of father sarcasm (squared semipartial $r=.14, t=3.46, p<.001$ ). These findings support the research hypothesis.

Finally, the univariate analyses for criticism indicated that the equation explained $14.64 \%$ of the variance $(F=6.17 ; d f=2 / 72, p<.003)$. Fathers' argumentativeness failed to contribute to the equation at the tradition .05 level of significance (squared partial $r=.05, t=1.85, p<.07$ ) when fathers' verbal aggression (squared semi-partial $r=.05$, $t=2.07, p<.04)$ was entered. In contrast to the nonsignificant correlations between 
TABLE 2 Correlations Between Predictors and Dependent Variables

\begin{tabular}{lcc} 
& \multicolumn{2}{c}{ Predictor Variable } \\
\cline { 2 - 3 } Dependent Variable & $\begin{array}{c}\text { Father's Verbal } \\
\text { Aggression }\end{array}$ & $\begin{array}{c}\text { Fathers' } \\
\text { Argumentativeness }\end{array}$ \\
\hline Sons' Perceived & $.40^{*}$ & .16 \\
Sarcasm & $(.32)^{*}$ & $(.13)$ \\
Sons' Perceived & $.50^{*}$ & .19 \\
Verbal Aggression & $(.44)^{*}$ & $(.17)$ \\
Sons' Perceived & $.33^{*}$ & $.31^{*}$ \\
Criticism & $(.25)^{*}$ & $(.24)^{*}$ \\
\hline
\end{tabular}

Note: Coefficients are corrected for attenuation. Uncorrelated coefficients are reported in parentheses. ${ }^{*} \mathrm{p}<.05$.

fathers' argumentativeness and the other two dependent measures, as Table 2 shows, fathers' argumentativeness correlated significantly with son's reports of father criticism.

\section{Discussion}

The present study was undertaken to examine the degree of association between fathers' verbal aggressiveness, controlling for fathers' argumentativeness, and sons' reports of fathers' sarcasm, criticism, and verbal aggressiveness. Accordingly, an equation consisting of fathers' argumentativeness and verbal aggressiveness (entered in that order) was used to predict sons' reports regarding fathers' communicative behavior. Overall, the results indicated substantial correspondence between fathers' and sons' reports. Specifically, approximately forty-percent of the variance in the sons' perceptions of fathers' messages was attributable to fathers' self-reported argumentativeness and verbal aggression.

Importantly, the pattern of results obtained in the present study supports the research hypothesis. Across the multivariate and follow-up univariate analyses, fathers' verbal aggression contributed unique variance to the prediction of adult sons' reports of father communication. In terms of Cohen's (1988) effect size benchmarks, the association between fathers' verbal aggression and the dependent variables was large for the full multivariate equation and for the univariate analysis of sons' perception of fathers' verbal aggression, slightly greater than medium for sarcasm, and slightly less than medium for criticism. $^{2}$

These results have two main implications for the study of interpersonal relationships between men and their fathers. First, the associations observed in the present study between fathers' self-reports and sons' perceptions provide validity evidence for adult sons' reports. Previous studies suggested that men's reports concerning their relationships with their fathers were correlated with various aspects of mens' social relationships. However, the source of mens' perceptions of their fathers was undocumented. These findings indicate that men's perceptions of fathers' verbal aggressiveness, sarcasm, and criticism are significantly based in their fathers' verbal aggressiveness.

Second, these results implicate men's perceptions of their fathers' verbal aggressiveness as intervening variables in men's social development. In addition to the consequences of father-adult son relationships reviewed at the outset, research has shown that fathers of impulsive and interpersonally insensitive college-aged men are more likely authoritarian than democratic in their parenting style (Brook, Brook, Whiteman, \& Gordon, 1983). Importantly, verbal aggressiveness has been linked to authoritarian approaches to parenting (Bayer \& Cegala, 1992). 
Some of the interpersonal consequences of adult son-father relationships (e.g., relational partners' perceptions of disconfirmation and apprehension) are mediated by the degree to which men feel confirmed or accepted by their fathers, which is largely a function of sons' interpretations of father messages (1993a, 1993b, 1993c). The correlations observed in the present study between fathers' verbal aggressiveness and adult sons' perceptions of their fathers' tendencies regarding communication suggest that men are conscious of their fathers' verbal behaviors. To the extent that sons attribute to their fathers motives that are consistent with the messages received, men's conclusions about their fathers' attitudes toward them are based on fathers' messages. In the men's literature, writers repeatedly allude to rejecting, uncaring, and even aggressive fathers (Bly, 1990; Lee, 1987, 1991). However, recent studies indicate that verbally aggressive people consider aggressive messages as less hurtful than do their verbally nonaggressive counterparts (Infante, Riddle, Horvath, \& Tumlin, 1992). Consequently, whether verbally aggressive fathers truly comprehend and appreciate the destructive potential of verbally aggressive tactics is a speculative matter at this point. If fathers' use of interpersonally destructive messages is largely unintentional, (mis)attribution processes might account for some of the interpersonal and social consequences of father-son relationships.

Furthermore, the usefulness of these findings to understanding men's social development is enhanced by examining the characteristics of verbally aggressive people. Rancer, Kosberg, and Silvestri (1992), among other things, studied the relationships between verbal aggressiveness and various dimensions of self-esteem. Relevant to this discussion, Rancer and his colleagues concluded that in contrast to verbally nonaggressive communicators, verbal aggressives are more defensive and less likely to exhibit self-control or admit mistakes. Under a trait conceptualization of verbal aggressivess, these types of responses can be viewed as characteristic of verbally aggressive people and somewhat independent of receiver behavior. As such, we would expect evidence of inappropriateness in verbally aggressive fathers' plans for dealing with a father-son conflict regardless of the son's characteristics. If sons, however, fail to differentiate between messages from verbally aggressive fathers, which are characteristic of the father's interaction style, from those which are receiver-adapted or situationally crafted, then sons are likely to attach unwarranted or exaggerated significance to their fathers' verbally aggressive remarks.

In conclusion, men's perceptions of their fathers' verbal aggressiveness appear to at least mediate various effects in the fathering process. As the preceding suggests, further study of the direct and indirect effects of fathers' communicative behavior on sons' development might provide useful information regarding the role of interpersonal communication in the socialization of men.

\section{NOTES}

1The original criticism and sarcasm scales were five and three items, respectively. We constructed two additional sarcasm items to render means between variables more comparable and to increase the internal consistency of the measure. The two items were: Centle-Harsh and Hostile-Amiable. Item total correlations were .59 and .56 . The addition of these items increased the reliability coefficient of the measure from .67 to .74 .

${ }^{2}$ Cohen (1988) points out that variance explained in multivariate cases cannot be interpreted exactly as in univariate analyses. The introduction of multiple dependent variables leads to an increased expectation regarding the multivariance. As a solution, Cohen (1988) recommends calculating $f^{2}$, which uses explained variance in the calculation but also adjusts for the number of dependent variables (for a discussion of formula and tables see pp. 477-481). Although $f^{2}$ is calculated differently for univariate and multivariate cases, the interpretation of the statistic is identical in both cases. Cohen $(1988$, p. 476$)$ recommends $f^{2}$ values of $.02, .15$, and .35 for small, medium, and large effects, respectively. 
The $f^{2}$ value for fathers' verbal aggression in the multivariate analysis was .44 . For the univariate analyzes of sons' perception of fathers' verbal aggressiveness, sarcasm, and criticism, the $f^{2}$ values were $.33, .19$, and .13 , respectively.

\section{REFERENCES}

Bayer, C. L., \& Cegala, D. J. (1992). Trait verbal aggressiveness and argumentativeness: Relations with parenting style. Western Journal of Communication, 56, 301-310.

Beatty, M. J., \& Dobos, J. A. (1992a). Adult sons' satisfaction with their relationships with fathers and person-group (father) communication apprehension. Communication Quarterly, 40, 162-176.

Beatty, M. J., \& Dobos, J. A. (1992b). Relationship between sons' perceptions of fathers' messages and satisfaction in adult son-father relationships. Southern Communication Journal, 57, 277-284.

Beatty, M. J., \& Dobos, J. A. (1993a). Adult males' perceptions of confirmation and relational partner communication apprehension: Indirect effects of fathers on sons' partners. Communication Quarterly, 47, 66-77.

Beatty, M. J., \& Dobos, J. A. (1993b). Direct and mediated effects of perceived father criticism and sarcasm on females' perceptions of relational partners' disconfirming behavior. Communication Quarterly, 41, 187-197.

Beatty, M. J., \& Dobos, J. A. (1993c). Mediated effects of adult males' perceived confirmation on females' perceptions of relational partners' disconfirming behavior. Southern Communication Journal, 58, 207-214.

Bly, R. (1990). Iron John: A book about men. Reading, MA: Addison-Wesley.

Brook, J. S., Brook, D., Whiteman, M., \& Gordon, A. S. (1983). Depressive mood in male college students: Father-son interaction patterns. Archives of General Psychiatry, 40, 665-669.

Cohen, \}. (1988). Power analysis for the social sciences (2nd ed.). Hillside, NJ: Lawrence Erlbaum.

Farmer, S. (1992). The wounded male. New York: Ballantine.

Infante, D. A. (1981). Trait argumentativeness as a predictor of communicative behavior in situations requiring argument. Central States Speech Journal, 32, 265-272.

Infante, D. A. (1987). Aggressiveness. In J. C. McCroskey \& J. A. Daly (Eds.), Personality and interpersonal communication. (pp. 175-192). Newbury Park: Sage.

Infante, D. A., Chandler, T. A., \& Rudd, J. E. (1989). Test of an argumentative skill deficiency model of interpersonal violence. Communication Monographs, 56, 163-177.

Infante, D. A., \& Rancer, A. S. (1982). A conceptualization and measure of argumentativeness. Journal of Personality Assessment, 46, 72-80.

Infante, D. A., Riddle, B. L., Horvath, C. L., \& Tumlin, S. A. (1992). Verbal aggressiveness: Messages and reasons. Communication Quarterly, 40, 116-126.

Infante, D. A., \& Wigley, C. J. (1986). Verbal aggressiveness: An interpersonal model and measure. Communication Monographs, 53, 61-69.

Lee, J. (1987). The flying boy: Healing the wounded man. Deerfield Beach, FL: Health Communication, Inc.

Lee, J. (1991). At my father's wedding: Reclaiming our true masculinity. New York: Bantam.

Osherson, S. (1986). Finding our fathers. New York: Ballantine.

Osherson, S. (1992). Wrestling with love: How men struggle with intimacy with women, children, parents, and each other. New York: Fawcett.

Pittman, F. (1993). Man enough: Fathers, sons, and the search for masculinity. New York: G. P. Putman's Sons.

Rancer, A. S., Baukus, R. A., \& Infante, D. A. (1985). Relations between argumentativeness and belief structure about arguing. Communication Education, 34, 37-47.

Rancer, A. S., Kosberg, R. L., \& Baukus, R. A. (1992). Beliefs about arguing as predictors of trait argumentativeness: Implications for training in argument and conflict management. Communication Education, 41, 375-382.

Rancer, A. S., Kosberg, R. L., \& Silvestri, V. N. (1992). The relationship between self-esteem and aggressive communication predispositions. Communication Research Reports, 9, $23-32$.

Sabourin, T. C., Infante, D. A., \& Rudd, J. E. (1993). A comparison of violent, distressed but nonviolent, and nondistressed couples. Human Communication Research, 20, 245-267.

Vogt, G. M., \& Sirridge, S. T. (1991). Like father, like son. New York: Anchor Press. 
Copyright of Communication Quarterly is the property of Eastern Communication Association and its content may not be copied or emailed to multiple sites or posted to a listserv without the copyright holder's express written permission. However, users may print, download, or email articles for individual use. 